\title{
Quality of life assessment of patients with schizophrenic spectrum disorders from Psychosocial Care Centers
}

\author{
Avaliação da qualidade de vida dos pacientes com transtorno \\ do espectro esquizofrênico atendidos nos Centros de \\ Atenção Psicossocial na cidade do Rio de Janeiro \\ Tatiana Fernandes Carpinteiro da Silva', Vanessa Mason², Lúcia Abelha', Giovanni Marcos Lovisi', \\ Maria Tavares Cavalcanti ${ }^{3}$
}

\section{RESUMO}

Objetivo: Avaliar a qualidade de vida e as características sociodemográficas e clínicas associadas em amostra de pacientes com transtorno do espectro esquizofrênico (CID-10 F20-F29) atendidos nos CAPS da área programática 3.0 da cidade do Rio de Janeiro. Métodos: Realizou-se estudo transversal em amostra de pacientes com diagnóstico pertencente ao espectro esquizofrênico, matriculados em 2008 nos CAPS da AP 3 da cidade do Rio de Janeiro. Foram utilizados instrumentos semiestruturados na avaliação da esquizofrenia e uso de álcool e drogas (MINIPLUS), sintomas psiquiátricos (PANSS) e qualidade de vida (QLS-BR). Resultados: Foram entrevistados 79 pacientes, dos quais 74 (93,7\%) tinham algum prejuízo na qualidade de vida. A área mais afetada foi o nível ocupacional. As variáveis que se mostraram significativamente associadas ao grave comprometimento da qualidade de vida foram: estado civil, raça, ocupação, com quem reside, situação de rua, ter filhos, internação psiquiátrica prévia, tipo sintomatológico negativo e não aplicável (sendo este caracterizado pela escassez dos típicos sintomas positivos e negativos). Conclusão: $O$ conhecimento desses fatores é importante para a formulação de políticas de saúde e programas de reabilitação psicossocial voltados para a otimização da qualidade de vida dessa clientela.

\begin{abstract}
Objective: Assessing the quality of life and the clinical and social-demographic factors associated in schizophrenic spectrum patients (ICD-10 F20-F29) attending CAPS at the programmatic area 3.0. Methods: A cross-sectional study was carried out in a sample of schizophrenic spectrum patients who have been enrolled in 2008 in CAPS in programmatic area (AP) 3 at Rio de Janeiro city, using MINIPLUS to assess schizophrenia spectrum disorder and use of psychoactive substances, Positive and Negative Symptoms Scale (PANSS) to assess psychiatric symptoms and Quality of Life Scale (QLS-BR) to assess the quality of life. Results: Seventy nine patients were included, of whom 74 (93.7\%) presented some impairment in quality of life. The most frequently affected area was occu-
\end{abstract}

1 Universidade Federal do Rio de Janeiro (UFRJ), Instituto de Estudos em Saúde Coletiva (IESC).

2 Columbia University, New York/USA.

Recebido em

$19 / 12 / 2010$

Aprovado em

3 Universidade Federal do Rio de Janeiro (UFRJ), Departamento de Psiquiatria e Medicina Legal (IPUB).

$14 / 3 / 2011$

Endereço para correspondência: Tatiana Fernandes Carpinteiro da Silva

Rua Professor Hermes de Lima, 264/301, Recreio - 22795-065 - Rio de Janeiro, RJ

E-mail: tatianafcs@bol.com.br 


\section{Keywords}

Schizophrenia, quality of life, mental health services, symptoms psychic. pational performance. Variables that showed a significant association with severe impairment of quality of life were: marital status, race, occupation, who patients lived with, homelessness, having children, previous psychiatric hospitalization, negative symptoms and symptoms designated as not applicable (being characterized by a lack of typical positive and negative symptoms). Conclusion: The knowledge of these factors should be crucial to implement health policies and psychosocial rehabilitation programs focused on improving the quality of life of these patients.

\section{INTRODUCTION}

Mental health care in Brazil has undergone a profound transformation since the mid 1970s with a shift in the direction of care from extensive hospitalization to a model generally located in the community, through the implementation of community-based mental health services ${ }^{1}$. The principal strategy adopted by the Ministry of Health for the execution of this policy of redirecting care was the implementation of Psychosocial Care Centers (CAPS). These centers are configured as regional community-based services in which patients receive not only medical consults but also multiprofessional individual or group therapy, participate in recreational activities planned as part of individualized therapy, connect to treatment and psychosocial rehabilitation, and offer extensive initiatives for family members and social issues present in the day-to-day lives of patients².

The population attended in CAPS is composed primarily of patients with severe mental illnesses, predominantly in the schizophrenic spectrum. Schizophrenia is considered to be one of the most severe mental disorders, unfavorably affecting the lives of individuals in various domains. It is characterized primarily by changes in perception of reality, including not only clinical changes, but also psychosocial changes, which are associated with its prognosis and quality of life impairment ${ }^{3}$.

Although quality of life does not have an agreed upon definition, the World Health Organization (WHO) conceptualizes it as the result of the interaction between social, economic, environmental, and health factors that affect human and social development. It is a broad definition which encompasses physical health, psychological wellbeing, level of independence, social relations, personal beliefs and relationship with the environment, being determined by the capacity to obtain necessary resources and maintain autonomy and independence in accordance with age $e^{4}$. It is known that in these patients quality of life can be affected in several areas like lack of social interaction, poor occupational performance, and unsatisfactory emotional-sexual relationships ${ }^{5-7}$.

In Brazil, few studies evaluated the quality of life of schizophrenic patients. They found severe impairment between $36 \%$ and $61 \%$ of cases, moderate impairment between $38 \%$ and $63 \%$ of cases and some degree of observed impairment found in almost all patients interviewed, around $80 \%$ to
95\% $\%^{6-10}$. The primary methodological limitations cited by authors of these studies were the use of cross-sectional studies, being restricted to institutionalized patients ${ }^{8}$ or patients who were clinically stable at the time of the interview, and not including patients with a history of psychoactive substance abuse, beyond the subjectivity of perception of quality of life for schizophrenic patients ${ }^{6,9,10}$.

The main objective of this study was to evaluate the quality of life and clinical and socio-demographic factors associated in a sample of patients with schizophrenic spectrum disorders enrolled in 2008 in CAPS in the city of Rio de Janeiro.

\section{METHODS}

\section{Setting and study population}

In Brazil, CAPS for adult care should include the following types of services: CAPS I, CAPS II, and CAPS III, from lower to higher complexity/size and population coverage ${ }^{11}$. The city of Rio de Janeiro had 10 CAPS II in 2008, with six located in the research area of the study (Programmatic Area 3 - PA3). The total number of patients enrolled in CAPS in Rio de Janeiro in 2007 was 3,061 individuals. Of these clients, around $64 \%$ were classified as patients with schizophrenic spectrum disorder ( $\mathrm{n}=1,956$ patients).

The study was conducted in five CAPS locate in PA3 which encompasses a population of 2.353 .590 inhabitants and serves $47.8 \%$ of the total population of patients enrolled in CAPS, divided in the following manner: PA3.1 - CAPS Ernesto Nazareth (Ilha do Governador) e CAPS Fernando Diniz (Olaria); PA3.2 - CAPS Clarice Lispector (Engenho de Dentro); PA3.3 - CAPS Rubens Corrêa (Irajá) e CAPS Linda Batista (Guadalupe). CAPS Torquato Neto (PA3.2) was not included as part of the study because it did not begin functioning until mid-2008.

The population of the study was comprised of 181 patients with schizophrenic spectrum disorder (ICD 10 between F20 and F29) enrolled in CAPS in PA3 in 2008, chosen that year for the availability of a complete list of patients enrolled. The sampling method followed a random process among patients whose medical records were put in a serial order list, from which the sample was randomly gathered. The 90\% expected frequency of quality of life impairment, 
$\pm 5 \%$ sampling error, $95 \%$ confidence level, were all taken into account to reach a sample size of 78 patients.

\section{Assessment instruments}

\section{Clinical and socio-demographic characteristics}

Socio-demographic and clinical data was collected including: sex, age, marital status, religion, schooling, race, birthplace, occupation, personal and familial monthly income, with whom the patient lived, previous psychiatric history, institutional history (nights spent in shelters, prisons or drug dependence treatment centers) and use of psychotropic medications.

\section{Diagnosis of schizophrenic spectrum disorder and use of psychoactive substances}

MINIPLUS was used for these assessments. It is a structured instrument composed of questions that examine symptoms and psychiatric syndromes to generate a psychiatric diagnosis. This instrument can be used after brief training (1-3 hours) requiring about 15 minutes to complete ${ }^{12}$. It was translated to Portuguese and validated in $2000^{13}$. In the present study, MINIPLUS was used to identify patients with schizophrenic spectrum disorder and patients with the disorder due to concurrent use of psychoactive substances.

\section{Psychiatric symptoms}

For the assessment of psychiatric symptoms, the Positive and Negative Syndrome Scale (PANSS) was used. It is a semi-structured instrument that assesses the presence and severity of psychopathological symptoms in the previous seven days. It is composed of 30 items, divided into positive, negative and psychopathological subscales. According to the scoring scale, four types of symptoms can be defined: positive, negative, mixed and not applicable ${ }^{14}$. PANSS was translated and validated for use in Brazil in $1993^{15}$.

\section{Assessment of quality of life}

The instrument used was the Quality of Life Scale specific to schizophrenic patients - QLS-BR. It is a semi-structured instrument composed of 21 items, validated for use in Brazil ${ }^{16}$. Besides overall assessment, the instrument allows the division in three subscales referring to social network, occupational level and intrapsychic functions/interpersonal relations. It should be used by a trained health professional and the interview lasts approximately 45 minutes $^{17}$. The final score is interpreted in the following manner: 0-2 major quality of life impairment; $\geq 2-4$ some degree of impairment in quality of life; $\geq 4$ quality of life unchanged. With the intention of evaluating which characteristics were associated with quality of life impairment and to facilitate data analysis, the assessment was categorized dichotomously as $<2$ and $\geq 2$, with a score $<2$ considered to be quality of life impairment. The scores could be categorized dichotomously because the patients rarely reach the maximum score range $(\geq 4)$, as observed in previous studies ${ }^{10}$.

\section{Procedure}

A cross sectional study was conducted with patients selected randomly from CAPS in programmatic area AP3 in the city of Rio de Janeiro. Data collection occurred from October 2009 to March 2010, led by five psychologists who received training in all of the instruments used. The study participants were selected from enrolled patients in CAPS in 2008, from information contained in the file for their diagnosis. Each registered patient with schizophrenic spectrum disorder was informed of the aim of the study and invited to participate in the research, requiring the signature of the free and informed consent form. Following signature, each participant was evaluated using MINIPLUS. If the patient was diagnosed with schizophrenic spectrum disorder, the other instruments were used in the following order: socio-demographic survey, PANSS, QLS-BR. In case the diagnosis was not confirmed, the use of other instruments did not occur.

\section{Ethical aspects}

The present study was approved by the Ethics and Research Committee of the Psychiatric Institute of the Federal University of Rio de Janeiro (685/09). Cases were identified through a numeric code and a separate list with the name of each participant maintained by the researchers.

\section{Statistical data analysis}

The prevalence of evaluated factors was calculated in the present study (with confidence interval of 95\%). Statistical tests of association were used, such as the chi-squared test and Fischer test for categorical variables and t-tests for continuous variables. All tests used a level of significance of $5 \%$. Odds ratios were estimated and their respective confidence intervals. SPSS 11.0.1 (Statistical Package for the Social Sciences) was used for data entry and analysis.

\section{RESULTS}

A total of 79 patients were interviewed, comprised of 44 men and 35 women. The mean age was 40.4 years, varying between 18 and 75 years of age (standard deviation $=12.9$ years). The majority of patients assessed were single (74.7\%), low level of schooling (81.0\% completed up to a basic level), native to Rio de Janeiro state (91.1\%), unemployed (60.8\%), received up to two minimum salaries (94.9\%), lived with relatives (84.8\%) and did not receive any social benefit (50.6\%). None were homeless at the time of the interview. However $21.5 \%$ of patients said that they had been homeless at some point during their lives. Among patients assessed, 33 (41.8\%) had children, comprised of 17 men and 16 women (Table 1). 
Table 1. Socio-demographic characteristics and their association with quality of life impairment in 79 schizophrenic spectrum patients attending CAPS in Rio de Janeiro in 2008 (Cl 95\%)

\begin{tabular}{|c|c|c|c|c|c|c|}
\hline \multirow{2}{*}{ Variable } & \multicolumn{2}{|c|}{ Total } & \multicolumn{2}{|c|}{ Impaired quality of life } & \multirow{2}{*}{ OR (C195\%) } & \multirow{2}{*}{$p$} \\
\hline & $\mathrm{n}$ & $\%$ & $n$ & $\%$ & & \\
\hline \multicolumn{7}{|l|}{ Sex } \\
\hline Male & 44 & 55.7 & 24 & 54.5 & 1 & \\
\hline Female & 35 & 44.3 & 21 & 60.0 & $0.8(0.3-2.0)$ & 0.63 \\
\hline \multicolumn{7}{|l|}{ Age group (years) } \\
\hline $18-29$ & 20 & 25.3 & 14 & 70.0 & 1 & \\
\hline $30-49$ & 36 & 45.6 & 18 & 50.0 & $1.8(0.5-6.3)$ & 0.36 \\
\hline$\geq 50$ & 23 & 29.1 & 13 & 56.5 & $2.3(0.7-7.4)$ & 0.15 \\
\hline \multicolumn{7}{|l|}{ Marital status } \\
\hline Single & 59 & 74.7 & 39 & 66.1 & 1 & \\
\hline Divorced & 9 & 11.4 & 3 & 33.3 & $3.9(0.9-17.3)$ & 0.07 \\
\hline Married & 8 & 10.1 & 1 & 12.5 & $13.6(1.6-118.5)$ & 0.01 \\
\hline Widower & 3 & 3.8 & 2 & 66.7 & $0.9(0.03-11.4)$ & 0.90 \\
\hline \multicolumn{7}{|l|}{ Schooling } \\
\hline$\leq 8$ years & 69 & 87.3 & 39 & 56.5 & 1 & \\
\hline$>8$ years & 10 & 12.7 & 6 & 60.0 & $0.9(0.2-3.3)$ & 0.84 \\
\hline \multicolumn{7}{|l|}{ Race } \\
\hline Others & 25 & 31.6 & 9 & 36.0 & 1 & \\
\hline White & 36 & 45.6 & 23 & 63.9 & $0.3(0.1-0.9)$ & 0.04 \\
\hline African & 18 & 22.8 & 13 & 72.2 & $0.2(0.06-0.8)$ & 0.02 \\
\hline \multicolumn{7}{|l|}{ Place of birth } \\
\hline Rio de Janeiro & 72 & 91.1 & 41 & 56.9 & 1 & \\
\hline Others & 7 & 8.9 & 4 & 57.1 & $1.0(0.2-4.8)$ & 0.71 \\
\hline \multicolumn{7}{|l|}{ Occupation } \\
\hline Retired & 20 & 25.3 & 11 & 55.0 & 1 & \\
\hline Employee & 11 & 13.9 & 1 & 9.1 & $12.2(1.3-114.4)$ & 0.03 \\
\hline Unemployed & 48 & 60.8 & 33 & 68.8 & $0.6(0.2-1.6)$ & 0.28 \\
\hline \multicolumn{7}{|l|}{ Personal monthly income } \\
\hline$\leq 2$ minimum wages & 75 & 94.9 & 43 & 57.3 & 1 & \\
\hline$>2$ minimum wages & 4 & 5.1 & 2 & 50.0 & $0.7(0.1-5.6)$ & 0.77 \\
\hline \multicolumn{7}{|l|}{ Family monthly income } \\
\hline$\leq 2$ minimum wages & 28 & 35.4 & 16 & 57.1 & 1 & \\
\hline $2-4$ minimum wages & 14 & 17.7 & 6 & 42.9 & $1.7(0.5-6.5)$ & 0.38 \\
\hline$>4$ minimum wages & 8 & 10.1 & 5 & 62.5 & $0.8(0.2-4.0)$ & 0.79 \\
\hline Not applicable & 29 & 36.7 & 18 & 62.1 & $0.8(0.3-2.4)$ & 0.71 \\
\hline \multicolumn{7}{|l|}{ Accommodations } \\
\hline Spouse & 8 & 10.1 & 1 & 12.5 & 1 & \\
\hline Alone & 12 & 15.2 & 7 & 58.3 & $0.1(0.01-1.1)$ & 0.06 \\
\hline Parents & 30 & 38.0 & 23 & 76.7 & $0.04(0.01-0.4)$ & $<0.01$ \\
\hline Other family & 22 & 27.8 & 10 & 45.5 & $0.2(0.02-1.6)$ & 0.12 \\
\hline 0thers & 7 & 8.9 & 4 & 57.1 & $0.1(0.01-1.4)$ & 0.09 \\
\hline \multicolumn{7}{|l|}{ Homelessness } \\
\hline No & 62 & 78.5 & 40 & 64.5 & 1 & \\
\hline Yes & 17 & 21.5 & 5 & 29.4 & $4.4(1.3-14.0)$ & 0.01 \\
\hline \multicolumn{7}{|l|}{ Social benefits } \\
\hline No & 40 & 50.6 & 25 & 62.5 & 1 & \\
\hline Yes & 39 & 49.4 & 20 & 51.3 & $1.6(0.6-3.9)$ & 0.32 \\
\hline \multicolumn{7}{|l|}{ Children } \\
\hline No & 46 & 58.2 & 35 & 76.1 & 1 & \\
\hline Yes & 33 & 41.8 & 10 & 30.3 & $7.3(2.7-19.9)$ & $<0.01$ \\
\hline
\end{tabular}

In relation to psychiatric factors, $82.3 \%$ had been previously admitted to inpatient facilities and $51.9 \%$ had purposely interrupted the use of medication. Nearly $56 \%$ said they required assistance in administering medication and only $16.5 \%$ of patients had their daily medication administered in
CAPS. Referring to the use of psychoactive substances, 21.5\% fulfilled criteria for disorders associated with the use of alcohol, while $16.5 \%$ possess some type of disorder associated to the use of illegal drugs. In relation to type of symptoms, a majority of patients had a mixed type (38\%) (Table 2). 
Table 2. Psychiatric factors and its association with quality of life impairment in 79 schizophrenic spectrum patients attending CAPS in Rio de Janeiro in 2008 (Cl 95\%)

\begin{tabular}{|c|c|c|c|c|c|c|}
\hline \multirow{2}{*}{ Variable } & \multicolumn{2}{|c|}{ Total } & \multicolumn{2}{|c|}{ Impaired quality of life } & \multirow{2}{*}{ OR (Cl 95\%) } & \multirow{2}{*}{$\mathbf{p}$} \\
\hline & $\mathrm{n}$ & $\%$ & $\mathrm{n}$ & $\%$ & & \\
\hline Previous psychiatric hospitalization & 65 & 82.3 & 33 & 50.8 & $5.8(1.2-28.1)$ & 0.03 \\
\hline Use of $\geq 3$ psychotropic medications & 36 & 45.6 & 18 & 50.0 & $1.7(0.7-4.1)$ & 0.25 \\
\hline Need help in medication & 44 & 55.7 & 29 & 65.9 & $0.4(0.2-1.1)$ & 0.07 \\
\hline Use medication in CAPS & 13 & 16.5 & 6 & 46.2 & $1.7(0.5-5.6)$ & 0.39 \\
\hline Use injectable medication & 12 & 15.2 & 5 & 41.7 & $2.1(0.6-7.2)$ & 0.25 \\
\hline Stopped medication on their own & 41 & 51.9 & 23 & 56.1 & $1.1(0.4-2.6)$ & 0.87 \\
\hline Previous clinic hospitalization & 25 & 31.6 & 11 & 44.0 & $2.2(0.8-5.7)$ & 0.11 \\
\hline Overnight in shelter/hostel & 11 & 13.9 & 7 & 63.6 & $0.7(0.2-2.7)$ & 0.63 \\
\hline Overnight in prision/detention & 11 & 13.9 & 4 & 36.4 & $2.7(0.7-10.0)$ & 0.15 \\
\hline Overnight in treatment center of dependence & 5 & 6.3 & 3 & 60.0 & $0.9(0.1-5.6)$ & 0.89 \\
\hline Disorder associated of alcohol use* & 17 & 21.5 & 8 & 47.1 & $1.7(0.6-4.9)$ & 0.35 \\
\hline Disorder associated of drugs use* & 13 & 16.5 & 7 & 53.8 & $1.2(0.4-3.8)$ & 0.80 \\
\hline Symptomatology type positive** & 8 & 10.1 & 4 & 50.0 & $1.4(0.3-5.9)$ & 0.68 \\
\hline Symptomatology type mixed ${ }^{* *}$ & 30 & 38.0 & 23 & 76.7 & $4.0(1.5-11.1)$ & 0.07 \\
\hline Symptomatology type negative** & 18 & 22.8 & 14 & 77.8 & $0.3(0.1-0.9)$ & 0.05 \\
\hline Symptomatology type $N A^{* *}$ & 23 & 29.1 & 4 & 17.4 & $13.0(3.8-44.4)$ & $<0.01$ \\
\hline
\end{tabular}

Within the overall assessment of quality of life, 93.7\% of patients evaluated presented some impairment (score $<4$ ), with $57 \%$ presenting severe impairment (score $<2$ ). Only five patients did not present a reduction in quality of life (6.3\%). The scaled score varied from 10 to 117 , with a mean of 2.02 after division by the total number of items (21). The item that presented the greatest impairment was the degree of unemployment (mean score 1.20) whereas the most scored item was the item related to common objects (mean 3.65). This last item presumes that the participation of the individual in the actual culture requires the possession of certain objects such as documentation, toothbrush, etc. Considering subscales, the factor occupational level demonstrated the greatest contribution to quality of life impairment in this population, with $74.7 \%$ of cases having a score of less than 2 or severe impairment. The factor social network also showed important impairment with $58.2 \%$ of patients interviewed presenting severe impairment (Table 3).

Socio-demographic variables that showed a significant association with severe impairment of quality of life were: marital status, race, occupation, who patients lived with, homelessness, and having children. Psychiatric factors significantly associated with quality of life impairment were: previous psychiatric hospitalization, negative symptoms and symptoms designated as not applicable.
Table 3. Distribution of average score per item of QLS-BR $(n=79)$

\begin{tabular}{lc}
\hline Item & Average \\
\hline Household & 2,71 \\
Friends & 1,61 \\
Acquaintances & 1,78 \\
Social activity & 1,34 \\
Social network & 2,06 \\
Social initiative & 1,57 \\
Withdrawal & 2,29 \\
Sociosexual & 1,46 \\
Occupatinal role & 1,34 \\
Work functioning & 1,22 \\
Work level & 1,20 \\
Work satisfaction & 1,42 \\
Sense of purpose & 1,85 \\
Motivation & 1,95 \\
Curiosity & 2,04 \\
Anhedonia & 2,01 \\
Aimless inactivity & 1,78 \\
Commonplace objects & 3,65 \\
Commonplace activities & 2,39 \\
Emphaty & 3,27 \\
Emotional interaction & 3,43 \\
SUBESCALES & \\
Social network & 1,91 \\
Instrumental role & 1,36 \\
Intrapsychic foundations/Interpersonal relations & 2,52 \\
TOTAL & 2,02 \\
\hline &
\end{tabular}




\section{DISCUSSION}

The proportion of patients with quality of life impairment was high with $93.7 \%$ presenting a score less than 4 on the QLS-BR, 36.3\% with moderate impairment and 57\% presenting severe impairment (score less than 2). Similar results were observed in different national and international researches $^{7,18-20}$. In a national study conducted with schizophrenic patients receiving outpatient treatment, moderate quality of life impairment was found in $63.4 \%$ of cases and severe impairment in $36.6 \%{ }^{10}$. In a study conducted with institutionalized patients (penitentiary hospital), moderate impairment was found in $38.9 \%$ of patients and severe impairment in $61.1 \%$ of patients ${ }^{8}$. This variation can be explained by the different samples of patients studied. The study that assessed patients attended as outpatients presented less quality of life impairment in comparison to other studies. This difference could be explained, hypothetically, by the fact that patients capable of maintaining outpatient treatment can present a smaller deterioration in their clinical and social chart in comparison to patients treated in CAPS, since CAPS receive patients with more severe disorders ${ }^{21}$. On the other hand, the study that evaluated institutionalized schizophrenic patients presented the most impaired quality of life, which was expected. However, the necessity of institutionalization can indicate a major impairment in this respect.

In the present study, the aspects of quality of life most affected were: degree of unemployment, level of occupational performance and fulfillment, demonstrating impairment at the occupational level. Unemployment was found in $60.8 \%$ of patients interviewed. Schizophrenic patients tend to present higher unemployment rate than the average of population in general. Furthermore, when these patients are employed tend to receive lower salaries than individuals who are not schizophrenic employed in similar positions. Factors that prevent schizophrenic patients from obtaining a job include stigma related to the disorder, lack of appropriate professional help and the fear of losing social benefits ${ }^{22}$. Some studies indicate working would promote an increase in the quality of life of schizophrenic patients, particularly greater wellbeing and greater satisfaction with finances and leisure ${ }^{23}$. In the present study, this association was not found. This could be understood when considering the difficulties involved in professional practices within this population. Of the 11 patients interviewed that had some sort of job, only one had formal employment. This indicates precariousness in occupational conditions for this population, which could explain the association with reduced quality of life. Studies that show a negative association between quality of life and occupation underline the fact that these patients described their occupations as stressful and demanding ${ }^{24}$.

The items related to social network also showed relevant impairment. Impairment was observed in patients' rela- tionships with their families and friends as well as little social activity and initiative and social withdraw. Various studies have indicated the direct relationship between social isolation and a worse prognosis for illness, not only at the time of onset of symptoms, but also during the course of the illness. Poor social functioning before the onset of symptoms is associated with a greater number of relapses, independent of the use of medication ${ }^{25}$. One study suggested that social maladjustment caused by schizophrenia develops according to a hierarchy, occurring first among peripheral social contacts (job performance and emotional relationships), followed by intimate contacts (relatives), and lastly affecting the capacity for personal care ${ }^{26}$. It is known that family support contributes positively to quality of life and recovery for these patients ${ }^{27}$. This supports results obtained in the present study, since residing with one's parents was shown to be associated with a better quality of life in this population. Stigma related to schizophrenia can impede social relationships, causing social isolation due to reasons such as fear or prejudice ${ }^{28}$.

In this study, racially identifying as black was shown to be associated with a better quality of life. Other studies did not prove the direct association between ethnicity and quality of life of schizophrenic patients, but stressed the influence of the interaction between race and socio-cultural aspects involved ${ }^{29}$. Racial identification as black has historically been unfavorable in Brazil in various aspects such as schooling, living conditions, employment, among others. The subjectivity of the assessment should be considered as individuals with lower expectations and aspirations come to consider more satisfactory in their quality of life ${ }^{30}$. The influence of psychotic disorders should also be considered in the ability of the patient to judge his own ethnicity. During the interview, various patients deemed race to be nonexistent, which led to an excess of classification in the category "others", possibly causing distortion in data analysis.

Several studies have shown the controversial relationship between quality of life of schizophrenic patients and the types of symptoms ${ }^{29}$. In this study, this association was observed for negative symptoms and mainly for symptoms designated as not applicable in PANSS. Symptoms that are not applicable represent those symptoms that are neither predominantly clinically positive symptoms or negative symptoms. These are cases in which general psychopathological symptoms such as anxiety, feelings of guilt, depression, somatic worry among others are most expressed ${ }^{14}$. Symptoms of depression and anxiety are often associated with poor quality of life, independent of the instrument used for measurement. It is assumed that these symptoms exercise greater influence on the quality of life in this population than positive symptoms and negative symptoms ${ }^{31}$. Similarly, association with reduced quality of life for symptoms designated as not applicable in this study can be explained by the pre- 
dominance of symptoms related to anxiety and depression. Similar results also have been observed in other studies ${ }^{18,32}$.

It is estimated that $2 \%-45 \%$ of the homeless suffer from schizophrenia ${ }^{33}$. Around $22 \%$ of the patients interviewed had already been homeless at some point during their lives. Of these, most were female, single, had little schooling and had children. The majority (64.7\%) was homeless on more than one occasion and $\mathbf{9 4 . 1 \%}$ of patients were homeless for less than one year. Being homeless was noted as a risk factor to quality of life impairment for these patients ${ }^{34}$, although at the time of interview, no patients were homeless with most residing with relatives. In relation to psychiatric history, $41.2 \%$ already had been hospitalized in psychiatric hospitals at least five times. About 29\% and 18\% presented a disorder associated with alcohol use and drug use respectively. This corroborates evidence that homeless patients have a greater prevalence of hospitalization, alcohol use and drug use than other patients ${ }^{35}$.

Although some studies have associated marriage with a better prognosis and better quality of life in these patients ${ }^{6}$, this association has not been consistently observed after controlling for age of onset of disease, since patients with early onset likely have a reduced chance of getting married ${ }^{36}$. In this study, being married was associated with a poorer quality of life. Regardless of onset of disease, symptoms can lead to social isolation, contributing to patients' difficulty in obtaining a stable relationship. For patients that married, schizophrenia can contribute to poor quality of the relationship for various reasons including, for example, inappropriate behavior that can be present in the active phase of the illness ${ }^{37}$.

Having children was shown to be associated with poor quality of life in patients interviewed. Of the 33 patients that have children, only 18\% lived with their children. Families of which one of the two parents has a mental illness tend to belong to lower economic classes, with a greater prevalence of domestic conflicts and family disintegration, in addition to the reduction in social and leisure activities, which could implicate a lower quality of life for these individuals ${ }^{38}$.

Of the patients interviewed, the great majority (82.3\%) had previous psychiatric hospitalizations, which is typical for this population in studies ${ }^{6,8}$. More than half of patients had purposely interrupted the use of medication during their treatment (51.9\%), and 55.7\% revealed that they required assistance to use their prescription medication. Only $16.5 \%$ receive medication in CAPS. Studies show that the proportion of non-adherence to treatment in schizophrenic patients is around $50 \%$. For depot medication, the proportion of non-adherence is less, varying from $14 \%$ to $36 \%$. In this study, only $15.2 \%$ received this kind of treatment regularly. It is known that non-adherence to treatment is associated with a greater number of relapses and longer duration of hospitalization ${ }^{39}$.

The presence of a disorder associated with alcohol use was detected in $21.5 \%$ of participants while $16.5 \%$ presented a disorder related to the use of illegal drugs. This comorbidity is common in schizophrenia. WHO estimates prevalence of $30 \%$ and $25 \%$ for alcohol use and use of illegal drugs respectively in schizophrenic patients, as much in patients in community-based treatment as patients interned ${ }^{3}$. The lower prevalence in the present study could be explained by the omission of information by patients. It should also be noted that this population is generally assisted by family, which results in increased supervision of patients, possibly contributing to the lower prevalence of these disorders. There was no observed association between alcohol use or illegal substance use to impairment of quality of life. This can be explained due to the increased level of social activity and larger social network of substance users in comparison to non substance users, which is necessary for obtaining and consuming these substances, besides presenting lower predominance of negative symptoms ${ }^{40}$.

The fact that the disorder primarily begins in youth contributes with patients do not have the opportunity to complete their studies generates obstacles to securing better employment and salaries. In this study, low level of schooling was found in $87.3 \%$ of patients interviewed. It is assumed that more education would increase the chance of gaining employment and having satisfactory job performance and consequently would contribute to a better quality of life for this population while reducing cognitive impairment. But this association is not always observed. Some studies associate greater schooling with reduced quality of life, which could be explained due to a larger judgment of morbidity and greater frustration among patients with higher levels of education ${ }^{20}$.

Low monthly income, family or individual, can also contribute to reduced quality of life. In the present study, of the 79 patients interviewed, 75 received less than two minimum salaries each month of which $48 \%$ received no income. Furthermore, only $49.4 \%$ of patients received some type of social benefits. In a multicenter study conducted in Europe, patients that received financial assistance from families or partners were more satisfied with their quality of life than patients that had some kind of occupation ${ }^{19}$. In a developing country like Brazil, factors such as low income, low level of schooling, and unemployment are present in populations without severe mental illness, which reduces the chances of schizophrenic individuals.

\section{CONCLUSION}

The assessment of factors associated with quality of life for patients with schizophrenia is fundamental for planning interventions that can improve the lives of patients. Quality of life impairment found in this study was high and associated primarily with factors such as marital status, race, occupation, who patients lived with, having children, homelessness, previous hospitalizations and type of symptoms. Therefore, psychosocial rehabilitation should be accompanied with greater attention to symptomatic treatment, identifying and avoiding anxious and depressive symptoms, beyond great 
assistance for the use of medication, to avoid relapses, and additionally the development of strategies to generate adequate employment for this population. It is also important to adopt measures that prevent homelessness and reduce the burden imposed by caring for children within this population. Improving quality of life in schizophrenia requires a multidimensional and multidisciplinary approach.

\section{Methodological limitations}

Due to the fact that the present study was cross sectional in nature, it is not possible to infer causal association between the evaluated factors and quality of life impairment. Another limitation is related to the fact that the study was conducted in only AP3 in the city of Rio de Janeiro. Although AP3 contains five of 10 CAPS II active during 2008, findings could have been the result of influence due to local peculiarities such as socio-cultural or violence-related issues.

\section{ACKNOWLEDGMENTS}

Conselho Nacional de Desenvolvimento Científico e Tecnológico (CNPQ).

\section{REFERENCES}

1. Mello MF, Mello AF, Kohn R. Epidemiologia da saúde mental no Brasil. Porto Alegre: Artmed; 2007.

2. Silva L. Doença mental, psicose, loucura: representações e práticas da equipe multiprofissional de um hospital-dia. São Paulo: Casa do Psicólogo; 2001.

3. World Health Organization. Nations for mental Health: Schizophrenia and Public Health. Geneva: World Health Organization; 1998.

4. World Health Organization. A glossary of terms for community health care and services for older persons. Geneva: World Health Organization; 2004

5. Priebe S. Social outcomes in schizophrenia. Br J Psychiatry. 2007;191:S15-20.

6. Cardoso C, Caiaffa W, Bandeira M, Siqueira A, Abreu M, Fonseca J. Qualidade de vida e dimensão ocupacional na esquizofrenia: uma comparação por sexo. Cad Saude Publica. 2006:22:1303-14.

7. Pinikahana J, Happell B, Hope J, Keks N. Quality of life in schizophrenia: a review of the literature from 1995 to 2000. Int J Ment Health Nurs. 2002;11:103-11.

8. Santana A, Chianca T, Cardoso C. Qualidade de vida de pacientes com esquizofrenia internados em hospital de custódia. J Bras Psiquiatr. 2009;58:187-94.

9. Cardoso C, Caiaffa W, Bandeira M, Siqueira A, Silva J, Fonseca J. Depressão na esquizofrenia: prevalência e relação com a qualidade de vida. Cad Saude Publica. 2007;23:2035-48.

10. Cardoso C, Caiaffa W, Bandeira M, Siqueira A, Abreu M, Fonseca J. Factors associated with a low quality of life in schizophrenia. Cad Saude Publica. 2005;21:1338-48.

11. Brasil. Ministério da Saúde. Secretaria de atenção à saúde/Dape. Saúde Mental no SUS: acesso ao tratamento e mudança do modelo de atenção. Relatório de Gestão 2003-2006. Brasília: Ministério da Saúde; 2007.

12. Sheehan D, Lecrubier Y, Sheehan K, Amorim P, Janavs J, Weiller E. The Mini International Neuropsychiatric Interview (MINI): The Development and Validation of a Structured Diagnostic Psychiatric Interview for DSM-IV and ICD-10. J Clin Psychiatry. 1998;59(Supl 20):22-33.

13. Amorim P. Mini International Neuropsychiatric Interview (MINI): validação de entrevista breve para diagnóstico de transtornos mentais. Rev Bras Psiquiatr. 2000;22:106-15.

14. Kay S, Fiszbein A, Opler L. The Positive and Negative Syndrome Scale for schizophrenia. Schizophr Bull. 1987;13:261-76.

15. Vessoni ALN. Adaptação e Estudo da Confiabilidade da Escala de Avaliação das Síndromes Positiva e Negativa para a Esquizofrenia no Brasil [tese]. São Paulo (SP): Escola Paulista de Medicina; 1993
16. Cardoso C, Bandeira M, Caiaffa W, Fonseca J. Escala de qualidade de vida para pacientes com esquizofrenia - QLS-BR: adaptação transcultural para o Brasil. J Bras Psiquiatr. 2002:51:31-8

17. Heinrichs D, Hanlon T, Carpenter W. The Quality of Life Scale: an instrument for rating the schizophrenic deficit syndrome. Schizophr Bull. 1984;10:388-98.

18. Solanki R, Singh P, Midha A, Chugh K. Schizophrenia: impact on quality of life. Indian J Psychiatry. 2008;50:181-6.

19. Kovess-Mafésty V, Xavier M, Kustner B, Suchoka A, Dedieu C, Dubuis J, et al. Schizophrenia and quality of life: a one year follow up in four EU countries. BMC Psychiatry. 2006;6:1-11.

20. Doyle M, Flanagan S, Browne S, Clarke M, Lydon D, Larkin C, et al. Subjective and external assessments of quality of life in schizophrenia: relationship to insight. Acta Psychiatr Scand. 1999;99:466-72

21. Cavalcanti M, Dahl C, Carvalho M, Valencia E. Critérios de admissão e cuidados em centros de atenção psicossocial, Rio de Janeiro, RJ. Rev Saude Publica. 2009:43:23-8.

22. Marwaha S, Johnson S. Schizophrenia and employment: a review. Soc Psychiatry Psychiatr Epidemiol. 2004;39:337-49.

23. Priebe S, Warner R, Hubschmid T, Eckle I. Employment, attitudes toward work, and quality of life among people with schizophrenia in three countries. Schizophr Bull. 1998;24:469-77.

24. Hofer A, Kemmler G, Eder U, Edlinger M, Hummer M, Fleischhacker W. Quality of life in schizophrenia: the impact of psychopathology, attitude toward medication, and side effects. J Clin Psychiatry. 2004;65:932-9.

25. Robinson D, Woerner M, Alvir J, Bilder R, Goldman R, Geisler S, et al. Predictors of releapse following response from a first episode of schizophrenia or schizoaffective disorder. Arch Gen Psychiatry. 1999;56:241-7.

26. De Jong A, Giel R, SlooffC, Wlersma D. Social disability and outcome in schizophrenic patients. Br J Psychiatry. 1985;147:631-6

27. Harvey C, Jeffreys S, McNaught A, Blizard R, King M. The Camden Schizophrenia Surveys III: five-year outcome of a sample of individuals from a prevalence survey and the importance of social relationships. Int J Soc Psychiatry. 2010;53:340-56.

28. Yanos P, Roe D, Markus K, Lysaker P. Pathways between internalized stigma and outcomes related to recovery in schizophrenia spectrum disorders. Psychiatr Serv. 2008;59:1437-42.

29. Souza L, Coutinho E. Fatores associados à qualidade de vida de pacientes com esquizofrenia. Rev Bras Psiquiatr. 2006;28:50-8.

30. Heringer R. Desigualdades raciais no Brasil: síntese de indicadores e desafios no campo das políticas públicas. Cad Saúde Pública. 2002;18:57-65.

31. Huppert J, Weiss L, Pratt S, Smith T. Quality of life in schizophrenia: contributions of anxiety and depression. Schizophr Res. 2001;51:171-80.

32. Galletly C, Clark R, MCFarlane A, Weber D. Relationships between changes in symptom ratings, neuropsychological test performance and quality of life in schizophrenic patients treated with clozapine. Psychiatry Res. 1997;72:161-6.

33. Folsom D, Jeste D. Schizophrenia in homeless persons: a systematic review of the literature. Acta Psychiatr Scand. 2002;105:404-13.

34. Lehman A, Kernan E, Deforge B, Dixon L. Effects of homeless on the quality of life of persons with severe mental illness. Psychiatr Serv. 1995;46:922-6.

35. Opler L, White L, Caton C, Dominguez B, Hirshfield S, Shrout P. Gender differences in the relationship of homelessness to symptom severity, substance abuse, and neuroleptic noncompliance in schizophrenia. J Nerv Ment Dis. 2001;189:449-56.

36. Eaton W, Mortensen P, Henman H, Freeman H, Bilker W, Burgess P, et al. Long-term course of hospitalization for schizophrenia. Part I: Risk for Rehospitalization. Schizophr Bull. 1992:18:217-28

37. Thara R, Srinivasan T. Outcome of marriage in schizophrenia. Soc Psychiatry Psychiatr Epidemiol. 1997:32:416-20

38. Australian Infant, Child, Adolescent and Family Mental Health Association (AICAFMHA), Scoping Project on Children of Parents with a Mental IIIness, Mental Health and Special Programs Branch of the Department of Health and Aged Care. NSW; 2001.

39. Rosa M, Elkis H. Adesão em esquizofrenia. Rev Psiq Clín. 2007;34:189-92.

40. Silva T, Legay L, Abelha L, Santos J, Lovisi G. Avaliação do ajustamento social em pacientes portadores de esquizofrenia atendidos em um ambulatório de hospital geral no Rio de Janeiro. Cad Saude Colet. 2010;18:587-96. 